\title{
High prevalence of prehypertension in mothers of young children in peri-urban Nepal
}

\author{
Vaidya $A^{1}$, Oli $N^{2,3}$, Krettek $A^{4,5,6}$
}

${ }^{1}$ Abhinav Vaidya, Associate Professor, Department of Community Medicine, Kathmandu Medical College, Kathmandu, Nepal; ${ }^{2}$ Natalia Oli, Lecturer, Department of Community Medicine, Kathmandu Medical College, Kathmandu, Nepal and ${ }^{3} \mathrm{PhD}$ student,Department of Internal Medicine and Clinical Nutrition, Institute of Medicine, Sahlgrenska Academy at University of Gothenburg, Gothenburg, Sweden; ${ }^{4}$ Alexandra Krettek, Professor, Department of Internal Medicine and Clinical Nutrition, Institute of Medicine, Sahlgrenska Academy at University of Gothenburg, Gothenburg, Sweden; ${ }^{5}$ Department of Biomedicine and Public Health, School of Health and Education, University of Skövde, Skövde, Sweden; ${ }^{6}$ Department of Community Medicine, Faculty of Health Sciences, UiT The Arctic University of Norway, Troms $\emptyset$, Norway

\begin{abstract}
Background: Prehypertension is clinically defined as a level of blood pressure between normal and hypertension, i.e. elevated systolic blood pressure between120-139 or diastolic blood pressure between 80-89 mm Hg. Prehypertension remains neglectedas a public health problem, and has not been explored in mothers with small childrenin Nepal.

Objectives: We aimed to study prehypertensionand its related factors including obesity-related parameters among mothers with children aged 1-7 years in Duwakot and Jhaukhel communities of Bhaktapur district, Nepal.

Methods: We prepared a sampling frame of all the eligible mothers, and interviewed 962 mothers. The trained enumerators also measured their blood pressure, body weight, height, waist and hip circumferences.We analysed data with SPSS version 22. We received ethical approval from the Nepal Health Research Council to conduct the study, and obtained informed verbal consent from the participating mothers.

Results: About one-third (31.8\%) of the mothers had prehypertension. It was more common among Newars and those aged 30-34 years. Multivariate analysis did not reveal significant association with sociodemographic variables except for education. We found positive correlations between blood pressure and obesity parameters.Overweight and obese participants were 2.24 (95\% confidence interval: 1.06-4.73) and 4.65 (95\% confidence interval: 1.92-11.23) times, respectively, more likely to have prehypertension than underweight mothers.

Conclusions: Our study demonstrated a high prevalence of prehypertension, coupled with high obesity parameters, among young mothers of peri-urban Nepal. Primordial preventive efforts at community level are needed not only for the mothers themselves, but for heart-health of their offspring as well.
\end{abstract}

Key words: Blood pressure, hypertension, obesity, prehypertension

\section{INTRODUCTION}

$\mathbf{P}^{\prime}$ rehypertension is defined as elevated systolic blood pressure (SBP)between120-139 or diastolic blood pressure (DBP) between $80-89 \mathrm{~mm} \mathrm{Hg}$, according to Joint National Committee (JNC) VII' ${ }^{1}$ Globally, prehypertension affects $25-50 \%$ of the adult population ${ }^{2}$, and $29 \%$ of adults of the South Asian region ${ }^{3}$. Although Nepal lacks official estimationof anational prehypertension

Address for correspondence

Dr. Abhinav Vaidya

Associate Professor, Department of Community Medicine

Kathmandu Medical College Teaching Hospital

Sinamangal, Kathmandu, Nepal

E-mail:dr.abhinavaidya@gmail.com prevalence, a meta-analysis based on a limited number of sub-national studies from Nepal estimates it to be $38 \%$, which corresponds to the highest prehypertension prevalence in the South Asian region ${ }^{3}$. Indeed, elevated blood pressure is a rising public health problem in $\mathrm{Nepal}^{4}$, with a quarter of the adults currently suffering from it ${ }^{5}$.

Blood pressure as a continuous physiological variable demonstrates a linearly increased risk of adverse cardiovascular outcome ${ }^{6}$. In this regard, the prehypertensive population carries higher cardiovascular risk than normotensive people ${ }^{2,7}$, including incident hypertension ${ }^{8}$. In fact, almost one-third of women who are prehypertensive at baseline become hypertensive at 
the end of three years ${ }^{9}$. Further, prehypertensive people are more likely than those with normotension to have at least one other risk factor ${ }^{10}$. Indeed, high prevalence of prehypertension and other components of the metabolic syndrome have also been demonstrated in Nepal ${ }^{11}$.

There are gender associated differences regarding blood pressure between men and women ${ }^{12}$. Although menhave higher blood pressure than women through much of their life, the prevalence of hypertension is predicted to increase more among women than menas the population ages ${ }^{12,13,14}$. Interestingly, more men $(31.1 \%)$ in Nepal have hypertension than women $(20.6 \%)^{5}$ but gender-wise variation for prehypertension is not known. Nonetheless, a study on rural Nepalese women revealedthat $14.4 \%$ of them are prehypertensive ${ }^{13}$.

Regarding women of reproductive age, especially young mothers, much of Nepal's public health attention has been on their nutritional and reproductive health issues ${ }^{14,15}$. Unlike the common perception thatwomen are less likely to suffer from cardiovascular diseases (CVDs) including elevated blood pressure,a high prevalence of hypertension has been reported among young adult females ${ }^{13,16}$ and high blood pressure is a rising trend in this specific sub-population too ${ }^{4}$.

Prehypertension, similar to hypertension, associates with various risk factors such as obesity, blood sugar level, and dyslipidemia ${ }^{17,18}$. Increased obesity parameters, both general and abdominal, are consistentlyrelated to higher prevalence of prehypertension ${ }^{17-20}$. Women in Nepal have high obesity parameters with approximately $22 \%$ and $5 \%$ being overweight and obese ${ }^{5}$, especially in urban ${ }^{21}$ and peri-urban ${ }^{22}$ settings due to various factors including low physical activity ${ }^{23}$.

To study population trends and perceptions on cardiovascular health in a peri-urban community, we started the Jhaukhel-Duwakot Health Demographic Surveillance Site (JD-HDSS) in the Bhaktapur district in 2010. Cardiovascular health emerged as an important but neglected issue in this community, particularly from the primary prevention perspective ${ }^{22-24}$. The aim of this paper was to specifically focus on mothers with children aged 1-7 years as mothersare the ones who are most involved in their children's behaviours related to cardiovascular risk factors including diet and physical activity ${ }^{25}$. We therefore estimated the extent of high blood pressure among mothers with emphasis on the concept of prehypertension and its association with obesity parameters.

\section{METHODS}

This is an observational cross-sectional study in JD-HDSS conducted in the Duwakot and Jhaukhel villages of Bhaktapur district, Nepal. We have previously reported the socio-demographic health status of these two adjoining communities ${ }^{26}$.

\section{SAMPLING AND SAMPLE SIZE}

We developed a sampling frame of all mothers from Duwakot and Jhaukhel with children aged 1-7 years. In case there was more than one eligible mother in a household, the enumerator applied a lottery method to select one mother. Altogether, there were 962 mothers eligible for inclusioninto the study.

\section{DATA COLLECTION}

Trained enumerators visited mothers house-tohouse, and interviewed them between September and December 2014. Enumerators also measured participants' blood pressure with Microlife digital devices; body weight with Microlife digital weighing machines; and anthropometric measurements (height, waist and hip circumferences) with non-stretchable measuring tapes. Blood pressure measurements were recorded three times in a gap of five minutes each. The average of three determinations was considered for data analysis. Blood pressure was classified according to JNC VII: normal $<120 \mathrm{mmHg}$ SBP and $<80 \mathrm{~mm} \mathrm{Hg}$ DBP; prehypertension : SBP between 120-139 or DBP between $80-89 \mathrm{~mm} \mathrm{Hg}$; and hypertension: $\geq 140 \mathrm{SBP}$ or $\geq$ $90 \mathrm{~mm} \mathrm{Hg} \mathrm{DBP}$ or a known case of hypertension treated with lifestyle modification and/or anti-hypertensive medication'. Increased waist circumference (WC) and waist hip ratio (WHR) were set as $\geq 80 \mathrm{~cm}^{27}$ and $\geq 0.85^{28}$, respectively.

We categorised socio-demographic variables as follows: age-group ( $<25,25-29,30-34$, and $\geq 35$ years); religion (Hinduism and others); ethnicity (the three most common ones in the community: Newar, Brahmin and Chhetri, and other ethnic groups such as Tamang, Rai, Thakuri and Dalitwere grouped into 'others' because of similarities in socio-cultural traits); education (categorised as $\leq$ grade 1 or less than primary, grade 1-5 or primary education, grade 6-10 or secondary education, and $>$ grade 10 or higher secondary education or more); occupation (housewives; agriculture and labour were grouped into one as there is often an overlap; employee included those who are self-employed or working in a government or a private firm); type of family (nuclear and joint); and household monthly income (Nepali Rupees $<10,000 ; 10,000-14,999 ; 15,000-19,999$; and $\geq 20,000$ ). 


\section{DATA ANALYSIS}

We entered data in Epidata version 2.0 and analysed it with Statistical Package for Social Sciences (SPSS) version 22. We presented categorical data in numbers and percentages, and tested their associations in bivariate analysis with chi-square test. We used Pearson's correlation test for bivariate analysis of continuous variables. We have presented strengths of associations with unadjusted and adjusted odds ratios and their $95 \%$ confidence intervals. $\mathrm{P}<0.05$ was considered statistically significant.

\section{ETHICAL ASPECTS}

The study received ethical approval from the Nepal Health Research Council (NHRC). We obtained informed verbal consent from the participating mothers and maintained confidentiality during data collection and data storage. Participants who were found to have elevated blood pressure were referred to Kathmandu Medical College Duwakot Hospital for counseling and treatment.

\section{RESULTS}

After excluding incompletely filled questionnaires, 916 mothers were included in the data analysis (Table 1). Mean age of the mothers was $29 \pm 4.6$ years (range: $19-48$ ). Most of them (88\%) were $\leq 35$ yearsold and $42 \%$ of them between 25-29 years. Ninety-two percent of them were Hindus. Most mothers belonged to the ethnic groups Chhetri (29\%), Newar (28\%) and Brahmin (22\%). Twenty three percent of the participants had education level of less than grade 1, whereas $29 \%$ had studied up to grade 10 or beyond. Most mothers (73\%) were housewives, while the rest were employed (17\%) or doing agriculture or labour work (10\%). Almost equal proportions of participants were living in nuclear (54\%) and joint (46\%) families. Information about monthly household income was available for 852 mothers. Of those, 11\% had Nepal Rupees $(\mathrm{NRP})<10,000$ while $42 \%$ had NRP $\geq 20,000$.

\section{PREVALENCE OF ELEVATED BLOOD PRESSURE}

Sixty percent of participants had normal blood pressure while the prevalence of prehypertension was $31.8 \%$. Table 1 shows the prevalences according to various socio-demographic parameters. Ten mothers reported having been diagnosed with high blood pressure $(10 / 916=1.1 \%)$. Of these, six were on medication $(6 / 10=60 \%)$. Of the six, only one had her blood pressure under control $(1 / 6=16.67 \%)$. Among the remaining 906 mothers, 69 were found to have high blood pressure during the survey $(69 / 916=7.5 \%)$. Hence, the prevalence of high blood pressure was $8.6 \%(1.1 \%+7.5 \%)$, and out of a total of 79 hypertensive mothers, only 10 knew that they had hypertension (awareness rate:12.65\%).

\section{RELATIONSHIP OF PREHYPERTENSION WITH SOCIO-DEMOGRAPHIC FACTORS}

Prehypertension was more common in the 30-34 years age group (37.9\%) and among Newars (38.5\%)(Table 1). After adjusting for possible confounders, those with lowest education ( $\leq$ grade 1 ) had 1.62 (95\% Cl: 1.04-2.5) times higher odds of having prehypertension compared to those with highest education (>grade 10) (Table 2). There were no significant associations for other sociodemographic variables.

\section{ASSOCIATION OF PREHYPERTENSION WITH OBESITY PARAMETERS}

We found a positive relationship between $\mathrm{BMI}$ and blood pressure status (Pearson correlation for SBP: 0.280 , $\mathrm{p}<0.001$; for DBP: $0.228, \mathrm{p}<0.001)$. This was additionally reflected in the prevalence of prehypertension, with 55\% of obese mothers having prehypertension compared to only $20 \%$ of underweight mothers (Table 3). Overweight and obese mothers were 2.24 (95\% Cl: 1.06-4.73) and 4.65 (95\% Cl: 1.92-11.23) times, respectively, more likely to have prehypertension than underweight mothers (Table 3).

Likewise, waist circumference exhibited a positive correlation both with SBP (Pearson correlation: 0.255, $\mathrm{p}<0.001$ ) and DBP (Pearson correlation: 0.243, $\mathrm{p}<0.001$ ). Those with increased waist circumference were 2.27 (95\% Cl: 1.56-3.30) times higher odds of having prehypertension than mothers with normal waist circumference (Table 3). There was a weak positive correlation between waist hip ratio and blood pressure (Pearson correlation for SBP: 0.131, $\mathrm{p}<0.001$, and DBP: $0.190, p<0.001)$. Mothers with increased waist hip ratio had 1.52 (95\% Cl:1.12-2.05) higher odds of having prehypertension (Table 3). 
Table 1: Blood pressure status of the study population according to their socio-demographic background

\begin{tabular}{|c|c|c|c|c|c|c|c|c|c|}
\hline & \multicolumn{6}{|c|}{ Blood pressure status } & \multirow{2}{*}{\multicolumn{2}{|c|}{ Total }} & \multirow{3}{*}{ p-value } \\
\hline & \multicolumn{2}{|c|}{ Normal } & \multicolumn{2}{|c|}{ Prehypertension } & \multicolumn{2}{|c|}{ Hypertension } & & & \\
\hline & $\mathbf{N}$ & $\%$ & $\mathbf{N}$ & $\%$ & $\mathbf{N}$ & $\%$ & $\mathbf{N}$ & $\%$ & \\
\hline \multicolumn{9}{|l|}{ Age (years) } & \multirow{5}{*}{0.018} \\
\hline$<25$ & 100 & 68.0 & 40 & 27.2 & 7 & 4.8 & 147 & 100.0 & \\
\hline $25-29$ & 242 & 63.9 & 109 & 28.8 & 28 & 7.4 & 379 & 100.0 & \\
\hline $30-34$ & 148 & 54.4 & 103 & 37.9 & 21 & 7.7 & 272 & 100.0 & \\
\hline$\geq 35$ & 56 & 51.9 & 39 & 36.1 & 13 & 12.0 & 108 & 100.0 & \\
\hline \multicolumn{10}{|l|}{ Religion } \\
\hline Hindu & 501 & 60.1 & 272 & 32.6 & 61 & 7.3 & 834 & 100.0 & \multirow{2}{*}{0.347} \\
\hline Non-Hindu ${ }^{a}$ & 45 & 62.5 & 19 & 26.4 & 8 & 11.1 & 72 & 100.0 & \\
\hline \multicolumn{9}{|l|}{ Ethnicity } & \multirow{5}{*}{0.022} \\
\hline Newar & 136 & 52.9 & 99 & 38.5 & 22 & 8.6 & 257 & 100.0 & \\
\hline Brahmin & 142 & 69.3 & 53 & 25.9 & 10 & 4.9 & 205 & 100.0 & \\
\hline Chhetri & 157 & 58.8 & 85 & 31.8 & 25 & 9.4 & 267 & 100.0 & \\
\hline Others $^{b}$ & 111 & 62.7 & 54 & 30.5 & 12 & 6.8 & 177 & 100.0 & \\
\hline \multicolumn{9}{|l|}{ Education } & \multirow{5}{*}{0.105} \\
\hline$<$ Grade 1 & 113 & 54.9 & 70 & 34.0 & 23 & 11.2 & 206 & 100.0 & \\
\hline Grade 1- 5 & 157 & 60.4 & 83 & 31.9 & 20 & 7.7 & 260 & 100.0 & \\
\hline Grade 6- 10 & 103 & 57.5 & 65 & 36.3 & 11 & 6.1 & 179 & 100.0 & \\
\hline$\geq$ Grade 10 & 173 & 66.3 & 73 & 28.0 & 15 & 5.7 & 261 & 100.0 & \\
\hline \multicolumn{9}{|l|}{ Occupation } & \multirow{4}{*}{0.300} \\
\hline Agriculture/labour & 54 & 57.4 & 32 & 34.0 & 8 & 8.5 & 94 & 100.0 & \\
\hline Employee & 102 & 66.2 & 46 & 29.9 & 6 & 3.9 & 154 & 100.0 & \\
\hline Housewife & 390 & 59.3 & 213 & 32.4 & 55 & 8.4 & 658 & 100.0 & \\
\hline \multicolumn{9}{|l|}{ Type of family } & \multirow{3}{*}{0.505} \\
\hline Joint & 252 & 60.7 & 136 & 32.8 & 27 & 6.5 & 415 & 100.0 & \\
\hline Nuclear & 294 & 59.9 & 155 & 31.6 & 42 & 8.6 & 491 & 100.0 & \\
\hline \multicolumn{9}{|c|}{ Household's monthly income (NRs) c } & \multirow{5}{*}{0.630} \\
\hline$<10000$ & 59 & 61.5 & 30 & 31.3 & 7 & 7.3 & 96 & 100.0 & \\
\hline $10000-14999$ & 141 & 61.3 & 71 & 30.9 & 18 & 7.8 & 230 & 100.0 & \\
\hline $15000-19999$ & 103 & 60.9 & 51 & 30.2 & 15 & 8.9 & 169 & 100.0 & \\
\hline$\geq 20000$ & 214 & 59.9 & 125 & 35.0 & 18 & 5.0 & 357 & 100.0 & \\
\hline
\end{tabular}

aNon-Hindu included Buddhists, Muslims and Christians ${ }^{\mathrm{b}}$ Others included Tamangs, Rais, Thakuris, Dalits, etc 'Nepali Rupees (1 US dollar equivalent to approx. NRs. 108) 
Table 2: Odds ratios of having prehypertension in comparison to those with normal blood pressure according to different socio-demographic factors

\begin{tabular}{|c|c|c|}
\hline & $\begin{array}{l}\text { Unadjusted Odds Ratio } \\
\qquad(95 \% \mathrm{Cl})\end{array}$ & $\begin{array}{l}\text { Adjusted Odds Ratio } \\
\qquad(95 \% \mathrm{CI})\end{array}$ \\
\hline \multicolumn{3}{|l|}{ Age (years) ${ }^{a}$} \\
\hline$\geq 35$ & $1.74(1.01-3.02)$ & $1.59(0.91-2.79)$ \\
\hline $30-34$ & $1.74(1.11-2.71)$ & $1.69(1.07-2.67)$ \\
\hline $25-29$ & $1.17(0.73-1.73)$ & $1.09(0.71-1.70)$ \\
\hline$<25$ & ref & ref \\
\hline \multicolumn{3}{|l|}{ Religion ${ }^{a}$} \\
\hline Hindu & $1.29(0.74-2.24)$ & $1.23(0.67-2.26)$ \\
\hline Non-Hindu & ref & ref \\
\hline \multicolumn{3}{|l|}{ Ethnicity $^{\mathrm{a}}$} \\
\hline Newar & $1.49(0.98-2.27)$ & $1.34(0.84-2.14)$ \\
\hline Brahmin & $0.76(0.49-1.20)$ & $0.67(0.39-1.14)$ \\
\hline Chhetri & $1.11(0.73-1.69)$ & $0.99(0.62-1.60)$ \\
\hline Others & ref & ref \\
\hline \multicolumn{3}{|l|}{ Education ${ }^{a}$} \\
\hline$<$ Grade 1 & $1.47(0.98-2.20)$ & $1.62(1.04-2.52)$ \\
\hline Grade 1- 5 & $1.25(0.85-1.83)$ & $1.334(0.897-1.985)$ \\
\hline Grade 6- 10 & $1.49(0.99-2.26)$ & $1.501(0.982-2.294)$ \\
\hline$\geq$ Grade 10 & ref & ref \\
\hline \multicolumn{3}{|l|}{ Occupation ${ }^{a}$} \\
\hline Agriculture/labour & $1.08(0.68-1.73)$ & $0.99(0.60-1.62)$ \\
\hline Employee & $0.83(0.56-1.21)$ & $0.80(0.53-1.21)$ \\
\hline Housewife & ref & ref \\
\hline \multicolumn{3}{|l|}{ Type of family } \\
\hline Joint & $1.024(0.770-1.361)$ & $1.035(0.765-1.401)$ \\
\hline Nuclear & ref & ref \\
\hline \multicolumn{3}{|c|}{ Household's monthly income (NRs.) a } \\
\hline$\geq 20000$ & $1.149(0.703-1.878)$ & $1.329(0.792-2.232)$ \\
\hline $15000-19999$ & $0.974(0.560-1.693)$ & $1.043(0.593-1.833)$ \\
\hline $10000-14999$ & $0.990(0.586-1.672)$ & $1.055(0.619-1.797)$ \\
\hline$<10000$ & ref & ref \\
\hline
\end{tabular}

ref: reference category; $\mathrm{Cl}$ : confidence interval

aodds ratios for age, religion, ethnicity, education, occupation, type of family and household monthly income were adjusted for socioeconomic variables other than the dependent variable itself. 
Table 3: Blood pressure status of the study population according to their obesity parameters

\begin{tabular}{|c|c|c|c|c|c|c|c|c|c|c|c|}
\hline & \multicolumn{6}{|c|}{ Blood pressure status } & \multirow{2}{*}{\multicolumn{4}{|c|}{$\begin{array}{l}\text { Odds Ratio ( } 95 \% \text { confidence interval)of } \\
\text { having prehypertension in comparison } \\
\text { to having normal blood pressure }\end{array}$}} & \multirow{3}{*}{ p-value } \\
\hline & \multicolumn{2}{|c|}{ Normal } & \multicolumn{2}{|c|}{ Prehypertension } & \multicolumn{2}{|c|}{ Hypertension } & & & & & \\
\hline & $\mathbf{N}$ & $\%$ & $\mathbf{N}$ & $\%$ & $\mathbf{N}$ & $\%$ & $\mathbf{N}$ & $\%$ & Unadjusted & Adjusted $^{d}$ & \\
\hline \multicolumn{12}{|c|}{ Body Mass Index ${ }^{a}$} \\
\hline Underweight & 35 & 71.4 & 10 & 20.4 & 4 & 8.2 & 49 & 100.0 & ref & ref & \multirow{4}{*}{$<0.001$} \\
\hline Normal & 323 & 67.3 & 128 & 26.7 & 29 & 6.0 & 480 & 100.0 & $1.39(0.67-2.89)$ & $1.286(0.615-2.686)$ & \\
\hline Overweight & 164 & 52.6 & 117 & 37.5 & 31 & 9.9 & 312 & 100.0 & $2.49(1.19-5.24)$ & $2.238(1.06-4.73)$ & \\
\hline Obese & 24 & 36.9 & 36 & 55.4 & 5 & 7.7 & 65 & 100.0 & $5.250(2.19-12.56)$ & $4.65(1.92-11.23)$ & \\
\hline \multicolumn{12}{|l|}{ Waist } \\
\hline Normal & 476 & 64.0 & 215 & 28.9 & 53 & 7.1 & 744 & 100.0 & ref & ref & \multirow{2}{*}{$<0.001$} \\
\hline Increased ${ }^{b}$ & 70 & 43.2 & 76 & 46.9 & 16 & 9.9 & 162 & 100.0 & $2.40(1.67-3.45)$ & $2.27(1.56-3.30)$ & \\
\hline \multicolumn{12}{|c|}{ Waist hip ratio } \\
\hline Normal & 379 & 63.9 & 174 & 29.3 & 40 & 6.7 & 593 & 100.0 & ref & ref & \multirow{2}{*}{0.008} \\
\hline Increased ${ }^{c}$ & 167 & 53.4 & 117 & 37.4 & 29 & 9.3 & 313 & 100.0 & $1.53(1.13-2.05)$ & $1.51(1.12-2.05)$ & \\
\hline
\end{tabular}

a Body mass index classified according to WHO classification (ref); ${ }^{b} \geq 80 \mathrm{~cm}^{\mathrm{c}} \geq 0.85$

dadjusted for socioeconomic variables

\section{DISCUSSION}

Our study demonstrated high prevalence (one-third) of prehypertension among peri-urban Nepalese mothers with young children. This prevalence is similar to that of Bangladeshi ${ }^{29}$ and Iranian women ${ }^{30}$; lower than the prevalence in rural women of West Bengal in India $(40.8 \%)^{31}$; and higher than that of Jamaican women $(25 \%)^{32}$. Similar high prevalence has earlier been reported in Nepalese women from hill origin ${ }^{13}$, and most of our mothers also belong to the same geographic background. In particular, mothers belonging to the Newari community in our study had high prevalence (38.5\%) of prehypertension, a finding also reported earlier for the general population in the same community ${ }^{33}$.

Mothers belonging to thehigher age group in our study had higher prevalence of prehypertension, a phenomenon which is seen in all populations ${ }^{1}$. Of concern is the fact that even among those who are younger than 25 years, more than a quarter of them hadprehypertension. This high occurrence of prehypertension in the relatively younger age group has been reported in North India too ${ }^{34}$. Unlike the previous Nepalese study ${ }^{13}$, mothers with higher income in our study had marginally higher prevalence of prehypertension (35\% vs. 31\%).

Our study specifically aimed to investigate the association between obesity parameters and prehypertension. More than a third of overweight mothers and more than half of obese mothers had prehypertension. The positive association between body weight and blood pressure is an establishedone ${ }^{35}$. This is of specific concern in these young mothers because there is high prevalence of overweight (one-third) and obesity (7\%) in these mothers- higher than the national average for women of similar age range ${ }^{5}$.

Health-care providers as well as the general population often have the misconception that blood pressure in the prehypertension range does not require intervention, and that people can continue with their lifestyle including dietary and physical activity behaviours ${ }^{36-39}$. Failure to adapt proper health behaviour if having prehypertension maylead to full-fledged hypertension and a greater difficulty to implement necessary lifestyle changes ${ }^{39-41}$. In fact, we reported earlier that there is a tendency among mothers in our peri-urban study setting to act, particularly in relation to diet and physical activity, only when they have been diagnosed as having a disease, including high blood pressure ${ }^{24}$. Therefore, it is important to communicate the significance of prehypertension at the population level. Those who are prehypertensive must be firmly and unambiguously advised to practice lifestyle modification to reduce their risk of developing hypertension in the future ${ }^{42}$. This is particularly true for the mothers in our study, because maintaining an unhealthy lifestyleis likelyto not only adversely affect their own health but may also negatively influence their children's choices regarding diet and physical activity ${ }^{25}$. 
Our study has some limitations. We did not ask the participants about other risk factors that could affect their blood pressure statussuch as smoking and alcohol behaviour ${ }^{17,43}$. Surprisingly, smoking was not associated with prehypertension in another Nepalese study on rural Nepalese women ${ }^{13}$. Furthermore, we did not inquire if participants were aware of their pre-pregnancy blood pressure. This would have provided the opportunity to explorethe possibility of pregnancy-induced high blood pressure, as many of the mothers may have continued to have chronic hypertension after developing pregnancyinduced hypertension. Indeed, similar to hypertension ${ }^{44}$, prehypertension also leads to adverse pregnancy and neonatal outcomes ${ }^{45}$, ${ }^{46}$. Hypertensive disorders of pregnancy are in fact the second commonest cause of maternal mortality in $\mathrm{Nepa}^{47}$, and this further underscores the importance of blood pressure control in Nepalese women. Because $86 \%$ of Nepalese pregnant women havetheir blood pressure measured during the antenatal visit ${ }^{14}$, extending counselling for those with

\section{REFERENCES}

1. Chobanian AV, Bakris GL, Black HR, Cushman WC, Green LA, Izzo JL Jr, et al. Seventh Report of the Joint National Committee on Prevention, Detection, Evaluation, and Treatment of High Blood Pressure. Hypertension. 2003;42(6):206-52.

2. Egan BM, Stevens-Fabry S. Prehypertension: prevalence, health risks, and management strategies. Nature reviews Cardiology. 2015;12(5):289-300.

3. Neupane D, McLachlan CS, Sharma R, Gyawali B, Khanal V, Mishra SR, et al. Prevalence of hypertension in member countries of South Asian Association for Regional Cooperation (SAARC): systematic review and meta-analysis. Medicine. 2014;93(13):e74.

4. Vaidya A, Pathak RP, Pandey MR. Prevalence of hypertension in Nepalese community triples in 25 years: a repeat cross-sectional study in rural Kathmandu. Indian heart journal. 2012;64(2):128-31.

5. Aryal KK, Mehata S, Neupane S, Vaidya A, Dhimal $M$, Dhakal $P$, et al. The Burden and Determinants of Non Communicable Diseases Risk Factors in Nepal: Findings from a Nationwide STEPS Survey. PLoS One. 2015;10(8):e0134834.

6. Rapsomaniki E, Timmis A, George J, PujadesRodriguez $M$, Shah AD, Denaxas $S$, et al. Blood pressure and incidence of twelve cardiovascular diseases: lifetime risks, healthy life-years lost, and age-specific associations in 1.25 million people. The Lancet. 383(9932):1899-911. prehypertension could be a cost-effective public health intervention ${ }^{48}$. For the women residing in Duwakot and Jhaukhel, screening during pregnancy could be a good entry point for blood pressure counselling as almost all (97\%) of them have at least one antenatal visit ${ }^{26}$. As Nepal faces many challenges forblood pressure prevention and control $^{49}$, paying attention to prehypertension could also be a useful addition to the ongoing preventive efforts focused on cardiovascular diseases.

\section{CONCLUSION}

Our study demonstrated a high prevalence of prehypertension in the peri-urban mothers of young children, particularly in the background of high obesity parameters, indicating need for primordial preventive efforts at community level that address behavioural cardiovascular risk factors. This is important not only for the mothers themselves, but for heart-health of their offspring as well.

7. Huang Y, Cai X, Liu C, Zhu D, Hua J, Hu Y, et al. Prehypertension and the risk of coronary heart disease in Asian and Western populations: a metaanalysis. J Am Heart Assoc. 2015 Feb;4(2):e001519.

8. Huang Y, Wang S, Cai X, Mai W, Hu Y, Hongfeng T, et al. Prehypertension and incidence of cardiovascular disease: a meta-analysis. BMC Medicine. 2013;11(1):19.

9. Zambrana RE, Lopez L, Dinwiddie GY, Ray RM, Phillips LS, Trevisan M, et al. Prevalence and incident prehypertension and hypertension in postmenopausal Hispanic women: results from the Women's Health Initiative. Am J Hypertens. 2014;27(3):372-81.

10. Greenlund KJ, Croft JB, Mensah GA. Prevalence of heart disease and stroke risk factors in persons with prehypertension in the United States, 1999-2000. Arch Intern Med. 2004;164(19):2113-8.

11. Sharma SK, Ghimire A, Radhakrishnan J, Thapa L, Shrestha NR, Paudel N, et al. Prevalence of hypertension, obesity, diabetes, and metabolic syndromeinNepal.IntJHypertens.2011;2011:821971.

12. Sandberg K, Ji H. Sex differences in primary hypertension. Biol Sex Differ. 2012 Mar 14;3(1):7.

13. Khan RJ, Stewart CP, Christian P, Schulze KJ, Wu L, Leclerq SC, et al. A cross-sectional study of the prevalence and risk factors for hypertension in rural Nepali women. BMC public health. 2013;13:55.

14. Ministry of Health and Population (MOHP) [Nepal], New ERA, and ICF International Inc. 2012. Nepal 
Demographic and Health Survey 2011. Kathmandu, Nepal: Ministry of Health and Population, New ERA, and ICF International, Calverton, Maryland.

15. Bhandari TR. Maternal health issues of Nepal and way forward. JHAS 2012;2:64-9.

16. Bhandari S, Sayami JT, Sayami M, Kandel BP, Banjara MR. General health status of women of reproductive age in Nepal. J Nepal Health Res Counc. 2014;12(26):813.

17. Guo X, Zou L, Zhang X, Li J, Zheng L, Sun Z, et al. Prehypertension: a meta-analysis of the epidemiology, risk factors, and predictors of progression. Tex Heart Inst J. 2011;38(6):643-52.

18. Zhang W, Li N. Prevalence, risk factors, and management of prehypertension. International journal of hypertension. 2011;2011:605359.

19. Ishikawa Y, Ishikawa J, Ishikawa S, Kajii E, Schwartz JE, Pickering TG, et al. Prehypertension and the risk for cardiovascular disease in the Japanese general population: the Jichi Medical School Cohort Study. J Hypertens. 2010;28:1630-37.

20. Kawamoto R, Kohara K, Tabara Y, Miki T. High Prevalence of Prehypertension is associated with the increased body mass index in community-dwelling Japanese. Tohoku J Exp Med. 2008;216(4):353-61. 21. Oli N, Vaidya A, Thapa G. Behavioural Risk Factors of Noncommunicable Diseases among Nepalese Urban Poor: A Descriptive Study from a Slum Area of Kathmandu. Epidemiology Research International. 2013;2013:13.

22. Vaidya A, Aryal UR, Krettek A. Cardiovascular health knowledge, attitude and practice/behaviour in an urbanising community of Nepal: a populationbased cross-sectional study from Jhaukhel-Duwakot Health Demographic Surveillance Site. BMJ open. 2013;3(10):e002976.

23. Vaidya A, Krettek A. Physical activity level and its sociodemographic correlates in a peri-urban Nepalese population: a cross-sectional study from the Jhaukhel-Duwakot health demographic surveillance site. Int J Behav Nutr Phys Act. 2014;11:39.

24. Oli N, Vaidya A, Subedi M, Krettek A. Experiences and perceptions about cause and prevention of cardiovascular disease among people with cardiometabolic conditions: findings of in-depth interviews from a peri-urban Nepalese community. Glob Health Action. 2014;7:10.

25. Oli N, Vaidya A, Subedi M, Krettek A. Diet and physical activity for children's health: a qualitative study of Nepalese mothers' perceptions. BMJ open. 2015;5(9):e008197.
26. Choulagai BP, Aryal UR, Shrestha B, Vaidya A, Onta $S$, Petzold $M$, et al. Jhaukhel-Duwakot Health Demographic Surveillance Site, Nepal: 2012 followup survey and use of skilled birth attendants. Glob Health Action. 2015 Dec 21;8:29396.

27. Lean M, Han T, Morrison C. Waist circumference as a measure for indicating need for weight management. Bmj. 1995;311(6998):158-61.

28. Jensen MD, Ryan DH, Apovian CM, Ard JD, Comuzzie AG, Donato KA, et al. 2013 AHA/ACC/TOS guideline for the management of overweight and obesity in adults: a report of the American College of Cardiology/American Heart Association Task Force on Practice Guidelines and The Obesity Society. Circulation. 2014;129(25 Suppl 2):S102-38.

29. Khanam MA, Lindeboom W, Razzaque A, Niessen $\mathrm{L}$, Milton $\mathrm{AH}$. Prevalence and determinants of prehypertension and hypertension among the adults in rural Bangladesh: findings from a communitybased study. BMC public health. 2015;15:203.

30. Rahmanian K, Shojaie M. The prevalence of prehypertension and its association to established cardiovascular risk factors in south of Iran. BMC research notes. 2012;5:386.

31. Dutta A, Ray MR. Prevalence of hypertension and prehypertension in rural women: a report from the villages of West Bengal, a state in the eastern part of India. Aust J Rural Health.2012;20(4):219-25.

32. Ferguson TS, Younger NO, Tulloch-Reid MK, Wright $M B L$, Ward EM, Ashley DE, et al. Prevalence of prehypertension and its relationship to risk factors for cardiovascular disease in Jamaica: analysis from a cross-sectional survey. BMC cardiovascular disorders. 2008;8:20.

33. Vaidya A. Is ethnicity an important determinant of high blood pressure in Nepalese population? A community-based cross sectional study in Duwakot, Nepal. Kathmandu Univ Med J. 2012;10(37):20-3.

34. Yadav S, Boddula R, Genitta G, Bhatia V, Bansal $B$, Kongara $S$, et al. Prevalence \& risk factors of prehypertension \& hypertension in an affluent north Indian population. Indian J Med Res. 2008 Dec;128(6):712-20.

35. Aune D, Sen A, Prasad M, Norat T, Janszky I, Tonstad $\mathrm{S}$, et al. BMI and all cause mortality: systematic review and non-linear dose-response meta-analysis of 230 cohort studies with 3.74 million deaths among 30.3 million participants. BMJ. 2016;353:i2156.

36. Bolli P, Hemmelgarn B, Myers MG, McKay D, Tremblay G, Tobe SW, et al. High normal blood pressure and prehypertension: The debate continues. Can J Cardiol.2007;23(7):581-3. 
37. Oke DA, Bandele EO. Misconceptions of hypertension. J Natl Med Assoc. 2004;96(9):1221-4.

38. Argulian E, Grossman E, Messerli FH. Misconceptions and facts about treating hypertension. Am J Med. 2015;128(5):450-5.

39. Khatib R, Schwalm JD, Yusuf S, Haynes RB, McKee M, Khan M, et al. Patient and Healthcare Provider Barriers to Hypertension Awareness, Treatment and Follow Up: A Systematic Review and Meta-Analysis of Qualitative and Quantitative Studies. PLoS One. 2014;9(1):e84238.

40. Scisney-Matlock M, Bosworth HB, Giger JN, Strickland OL, Harrison RV, Coverson D, et al. Strategies for implementing and sustaining therapeutic lifestyle changes as part of hypertension management in African Americans. Postgrad Med. 2009;121(3):14759.

41. Habib GB, Virani SS, Jneid H. Is 2015 the primetime year for prehypertension? Prehypertension: a cardiovascular risk factor or simply a risk marker? J Am Heart Assoc. 2015 Feb;4(2):e001792.

42. Gupta P, Nagaraju SP, Gupta A, Mandya Chikkalingaiah KB. Prehypertension - time to act. Saudi J Kidney Dis Transpl. 2012;23(2):223-33.
43. Zhang W, Li N. Prevalence, Risk Factors, and Management of Prehypertension. Int J Hypertens. 2011;2011:6053-9.

44. Kintiraki E, Papakatsika S, Kotronis G, Goulis DG, Kotsis V. Pregnancy-Induced hypertension. Hormones (Athens). 2015;14(2):211-23.

45. Wikström A-K, Gunnarsdottir J, Nelander M,SimicM, Stephansson O, Cnattingius S. Prehypertension in Pregnancy and Risks of Small for Gestational Age Infant and Stillbirth.Hypertension. 2016;67(3):640-6.

46. Rosner JY, Gutierrez M, Dziadosz M, Pham A, Bennett TA, Dolin C, et al. Prehypertension in Early Pregnancy: What is the Significance? Am J Perinatol. 2016 Jun 20. [Epub ahead of print]

47. Choudhary P. Eclampsia: a hospital based retrospective study. Kathmandu University medical journal (KUMJ). 2003;1(4):237-41.

48. Egan BM, Lackland DT, Jones DW. Prehypertension: an opportunity for a new public health paradigm. Cardiol Clin. 2010;28(4):561-9.

49. Dhitali SM, Karki A. Dealing with the burden of hypertension in Nepal: current status, challenges and health system issues. Regional Health Forum. 2013;17(1):9. 